\title{
PENGARUH LINGKUNGAN KERJA TERHADAP SEMANGAT KERJA GURU PADA SMK NEGERI 1 UKUI
}

\author{
Nova Safrina, Vina Lestari \\ Sekolah Tinggi Ilmu Ekonomi Riau \\ e-mail: nova.syafrina80@gmail.com
}

\begin{abstract}
This research was conducted at SMK Negeri 1 UKUI. With the aim of research to find out. Environment. The population in this study were all teachers at SMK Negeri 1 UKUI, while the samples in this study were 31 teachers. Analysis of the data used is validity test, reliability test, normality test, simple linear regression test and test coefficient of determination. While the hypothesis test uses the test. The results of this study are positive and significant work environment variables on teacher morale at UKUI Vocational High School 1. At the time of regression, the equation $Y=-2.588+0.898 X$, and the test coefficient of determination which contributes to the work environment is $90.6 \%$.
\end{abstract}

Keywords: Work Environment, Work Spirit

\begin{abstract}
Abstrak
Penelitian ini dilakukan di SMK Negeri 1 UKUI. Dengan tujuan penelitian untuk mengetahui Pengaruh lingkungan kerja terhadap semangat kerja guru SMK Negeri 1 UKUI. Populasi dalam penelitian ini adalah seluruh guru pada SMK Negeri 1 UKUI, sedangkan sampel dalam penelitian ini adalah sebanyak 31 guru. Analisis data yang digunakan adalah uji validitas, uji reliabilitas, Uji normalitas, uji regresi linear sederhana dan uji koefisien determinasi. Sedangkan uji hipotesis menggunakan uji t. Hasil penelitian ini bahwa variabel lingkungan kerja berpengaruh positif dan signifikan terhadap semangat kerja guru pada SMK Negeri 1 UKUI. Pada uji regresi didapat persamaan $Y=-2,588+0,898 X$, dan pada uji koefisien determinasi bahwa lingkungan kerja memberikan sumbangan pengaruh terhadap semangat kerja sebesar 90,6\%.
\end{abstract}

Kata Kunci : Lingkungan Kerja, Semangat Kerja

\section{PENDAHULUAN}

Peran manusia di dalam organisasi merupakan modal dasar dalam menentukan tercapai atau tidaknya tujuan dari organisasi yang telah ditetapkan di mana semangat kerja karyawan sangat menentukan maju mundurnya suatu organisasi.Banyak organisasi yang mengalami perubahan dalam lingkungan yang semakin kompetitif ketidakpuasan karyawan mungkin akan lebih banyak terjadi,. Ketika ketidakpuasan terjadi, stabilitas dan keberhasilan organisasi akan terhambat. Dengan menciptakan lingkungan kerja yang baik di perusahaan maka akan dapat mendukung suasana kerja yang baik pula dimana ini akan menimbulkan motivasi kerja yang tinggi serta dapat membangkitkan semangat kerja para karyawan guna mencapai tingkat produktifitas (Siagian, 2009:289) .

Dari bentuk fisik lingkungan kerja yang baik meliputi penerangan yang cukup, tempat yang bersih, tersedianya alat-alat pengaman, sirkulasi udara yang baik, suara bising yang dapat di tekan seminimal mungkin, Tersedianya fasilitas pendukung lainya. Dengan adanya fasilitas-fasilitas yang diberikan perusahaan, maka hal ini sangat berpengaruh langsung terhadap semangat kerja karyawan sehingga akan memberikan implikasi yang baik pula bagi perusahaan.

Selain lingkungan fisik, lingkungan non fisik juga berpengaruh terhadap semangat kerja karyawan, lingkungan yang bersifat batiniah seperti hubungan pertemanan atau hubungan sosial antara 
anggota organisasi. Lingkungan non fisik merupakan lingkungan yang tidak bisa diabaikan, perusahaan hendaknya memcerminkan kondisi kerja yang mendukung kerja satu sama lain, kondisi yang diciptakan hendaknya bersifat kekeluargaan, komunikasi yang baik dan pengendalian diri.

Membina hubungan yang baik antara sesama rekan kerja harus dilakukan karna saling membutuhkan. Hubungan kerja yang terbentuk sangat mempengaruhi psikologis karyawan.

Sekolah Menengah Kejuruan (SMK) Negeri 1 UKUI Kabupaten Pelalawan adalah salah satu instansi pemerintah yang bertugas dalam bidang pendidikan dasar. Pekembangan pendidikan sangat diperlukan guna mencetak anak bangsa yang berkualitas, terampil dan berakhlak mulia. Hal ini diperlukan tenaga pendidik yang berkualitas dan memiliki wawasan dengan perkembangan Ilmu Pengetahuan dan Teknologi (IPTEK). Berikut dapat dilihat jumlah tenaga pengajar pada SMK Negeri 1 UKUI.

Tabel 1 Data Guru SMK Negeri 1 UKUI Tahun 2013-2017

\begin{tabular}{ccc}
\hline $\begin{array}{c}\text { Tahun } \\
\text { Pelajaran }\end{array}$ & $\begin{array}{c}\text { Jumlah } \\
\text { Guru }\end{array}$ & Perkembangan \\
\hline $2013 / 2014$ & 25 & 0 \\
\hline $2014 / 2015$ & 27 & $8 \%$ \\
\hline $2015 / 2016$ & 35 & $29,63 \%$ \\
\hline $2016 / 2017$ & 33 & $-5,71 \%$ \\
\hline $2017 / 2018$ & 31 & $-6,06 \%$ \\
\hline
\end{tabular}

Sumber: SMK Negeri 1 UKUI 2018

Dari tabel 1 dapat dilihat bahwa tenaga pengajar setiap tahunnya mengalami perubahan, baik penambahan maupun pengurangan. Hal ini dapat mempengaruhi kualitas kerja guru dalam melaksanakan proses belajar mengajar. Dengan bertambahnya guru yang profesional, dapat meningkatkan kualitas lulusan pada SMK Negeri 1 UKUI. Berikut adalah data kehadiran guru SMK Negeri 1 UKUI dalam lima tahun terakhir.

\begin{tabular}{|c|c|c|c|c|c|}
\hline Tahun & $\begin{array}{l}\text { Jlh. } \\
\text { Guru }\end{array}$ & $\begin{array}{c}\text { Hari } \\
\text { Efektif/Thn }\end{array}$ & $\begin{array}{c}\text { Jlh } \\
\text { Hari } \\
\text { Kerja/ } \\
\text { Thn }\end{array}$ & Alpa & $\begin{array}{c}\text { Persentase } \\
\text { Perkembangan }\end{array}$ \\
\hline 2013 & 25 & 235 & 5.875 & 54 & 0 \\
\hline 2014 & 27 & 287 & 7.749 & 75 & $38,89 \%$ \\
\hline 2015 & 35 & 240 & 8.400 & 48 & $-36 \%$ \\
\hline 2016 & 33 & 235 & 7.755 & 89 & $85,42 \%$ \\
\hline 2017 & 31 & 235 & 7.285 & 115 & $29,21 \%$ \\
\hline
\end{tabular}

Sumber: SMK Negeri 1 UKUI 2018

Dari tabel 2 dapat dilihat tingkat absensi guru pada SMK Negeri 1 UKUI selalu mengalami kenaikan pada tahun 2013, 2015 dan 2016. Hal ini salah satunya kemungkinan dipengaruhi oleh lingkungan kerja yang kurang memadai, sehingga guru kurang bersemangat dalam melakukan proses belajar mengajar. Berikut dapat kita lihat data sarana dan prasarana pada SMK Negeri 1 UKUI. 
Tabel 3. Data Sarana dan Prasarana SMK Negeri 1 UKUI Tahun 2017

\begin{tabular}{lccc}
\hline \multicolumn{1}{c}{ Jenis Ruang } & Jumlah & $\begin{array}{c}\text { Luas } \\
\left(\mathrm{M}^{2}\right)\end{array}$ & $\begin{array}{c}\text { Kondisi } \\
\text { Kerusakan }\end{array}$ \\
\hline Bengkel TSM & 1 & $72 \mathrm{M}^{2}$ & $5,28 \%$ \\
\hline Ruang Guru & 1 & $81 \mathrm{M}^{2}$ & $4,61 \%$ \\
\hline Lab. Komputer & 1 & $240 \mathrm{M}^{2}$ & $5,81 \%$ \\
\hline Perpustakaan & 1 & $64 \mathrm{M}^{2}$ & $5,17 \%$ \\
\hline Ruang Kepsek & 1 & $12 \mathrm{M}^{2}$ & $4,51 \%$ \\
\hline Ruang Osis & 1 & $72 \mathrm{M}^{2}$ & $5,54 \%$ \\
\hline Ruang Pic & 1 & $72 \mathrm{M}^{2}$ & $3,51 \%$ \\
\hline UKS & 1 & $12 \mathrm{M}^{2}$ & $4,44 \%$ \\
\hline WC Siswa & 2 & $16 \mathrm{M}^{2}$ & $5,81 \%$ \\
\hline $\begin{array}{l}\text { Workshop } \\
\text { Otomotif }\end{array}$ & 1 & $240 \mathrm{M}^{2}$ & $6,29 \%$ \\
\hline $\begin{array}{l}\text { 16 Ruang Kelas } \\
\text { Meja dan Kursi }\end{array}$ & 394 set & 1.152 & $5,21 \%$ \\
Siswa & & & \\
\hline Papan Tulis & 17 bh & - & \\
\hline $\begin{array}{l}\text { Meja dan Kursi } \\
\text { Guru set }\end{array}$ & 32 13 set di kantor Guru \\
\hline
\end{tabular}

Sumber: SMK Negeri 1 UKUI 2018

Dari tabel 3 dapat kita lihat bahwa sarana dan prasarana SMK Negeri 1 UKUI Kerinci masih kurang. Dengan jumlah guru 31 orang, meja dan kursi guru yang tersedia di kantor guru hanya 13 set. Berarti masih terdapat kekurangan meja dan kursi guru di kantor guru 18 set. Hal ini akan membuat guru lebih suka pulang dari pada duduk di kantor jika tidak ada jam mengajar. Selain kurangnya meja dan kursi guru, prasarana pada SMK Negeri 1 UKUI juga masih perlu perbaikan, hal ini dapat kita lihat bahwa setiap ruangan masih terdapat tingkat kerusakan walaupun hanya kisaran 3\%-7\% saja. Hal ini jika tidak ditindak lanjuti dengan baik, bisa jadi kerusakan akan mengalami pemanbahan.

\section{METODE}

\subsection{Tempat Penelitian}

Penelitian ini dilakukan di SMK Negeri 1 UKUI yang beralamat di Jl. Lintas Timur Ukui Dua, Ukui 2, UKUI, KAB. PELALAWAN 29353.

\subsection{Teknik Pengumpulan Data}

Dalam penulisan skripsi ini, penulis menggunakan cara pengumpulan data sebagai berikut :

a. Kuisioner. Kuisioner adalah daftar pertanyaan yang disebarkan kepada seluruh guru SMK Negeri 1 UKUI. Untuk mengetahui pengaruh kompensasi terhadap kinerja guru digunakan skala likert. Skala likert digunakan untuk mengukur sikap, pendapat dan presepsi seseorang atau kelompok orang tentang fenomenal sosial. Dengan skala likert, maka variabel yang diukur dan dijabarkan menjadi indikator variabel. Jawaban setiap item yang menggunakan skala likert mempunyai gradiasi dan sangat positif sampai sangat negatif. (Sugiyono, 2010:107). 
b. Wawancara. Wawancara adalah mengadakan wawancara langsung pada kepala sekolah dan guru SMK Negeri 1 UKUI tentang berbagai informasi/data, untuk bahan analisa yang diperlukan dalam penulisan skripsi ini.

\subsection{Analisis Data}

Analisis data yang digunakan dalam penelitian ini adalah metode analisis deskriptif dan kuantitatif. Dalam penelitian ini digunakan model analisis regresi linear sederhana dengan menggunakan alat bantu program SPSS.19 (Statistical Package for Social Science) yaitu analisis tentang hubungan antara satu dependent variabel dengan satu independent variabel. (Suharsimi Arikunto, 2010:339)

\section{Uji Validitas}

Uji Validitas. Ghozali dalam Sujarweni (2015:165) uji validitas digunakan untuk mengukur sah atau valid tidaknya suatu kuesioner. Dengan demikian, instrumen yang valid merupakan instrumen yang benar-benar tepat untuk mengukur apa yang hendak di ukur. Uji validitas berguna untuk mengetahui apakah ada pemyataan-pernyataan pada kuesioner yang harus dibuang/diganti karena dianggap tidak relevan. Pengujian uji validitas dengan menggunkan uji dua sisi dengan taraf signifikansi 0,05. Kriteria Pengujian adalah sebagai berikut : (Duwi Priyatno, 2008:18)

1. Jika $r$ hitung $>\mathrm{r}$ tabel ( $\mathrm{r}$ tabel didapat dari seluruh sampel yang akan diujikan yaitu $\mathrm{N}=31$ orang guru SMK Negeri 1 UKUI yaitu sebesar 0,355) (uji 2 sisi dengan sig 0,05) maka instrument atau itemitem pertanyaan berkorelasi signifikan terhadap skor total (dinyatakan valid).

2. Jika $r$ hitung $<r$ tabel (uji 2 sisi dengan sig. 0,05) maka instrument atau item-item pertanyaan tidak berkorelasi signifikan terhadap skor total (dinyatakan tidak valid).

\section{Uji Reliabilitas.}

Uji reliabilitas berguna untuk menetapkan apakah instrumen yang dalam hal ini kuesioner dapat digunakan lebih dan satu kali, paling tidak oleh responden yang sama akan menghasilkan data yang konsisten. Dengan kata lain, reliabilitas instrumen mencirikan tingkat konsistensi. Nilai koefisien reliabilitas yang baik adalah diatas 0,6 ( kuat), di atas 0,8 (sangat kuat). (Sugiyono, 2010:214)

\section{Uji Regresi Linear Sederhana}

Analisis regresi sederhana adalah analisis untuk mengukur besarnya pengaruh antara satu variabel independen dengan satu variabel dependen. Analisis ini digunakan untuk mengetahui arah hubungan antara variabel independen dengan variabel dependen apakah positif atau negatif dan untuk memprediksi nilai dari variabel dependen apabila nilai variabel independen mengalami kenaikan atau penurunan. Data yang digunakan biasanya berskala interval atau rasio. Rumus regresi linear sederhana menurut (Sugiyono, 2012:270) adalah sebagai berikut :

$$
\begin{aligned}
& \mathrm{Y}=\mathrm{a}+\mathrm{bX}+\varepsilon \\
& \text { Keterangan: } \\
& \mathrm{Y} \quad=\text { Semangat Kerja. } \\
& \mathrm{a} \quad=\text { Konstanta } \\
& \mathrm{b} \quad=\text { Koefisien regresi } \\
& \mathrm{X}=\text { Lingkungan Kerja. } \\
& \varepsilon \quad=\text { Standar error }
\end{aligned}
$$

\section{Uji Koefisien Determinasi}

Analisis determinasi dalam regresi linear sederhana yang digunakan untuk mengetahui persentase sumbangan pengaruh variabel independen terhadap variabel dependen (Y). Koefisien ini menunjukkan seberapa besar persentase variasi variabel independen yang digunakan dalam model dan mampu menjelaskan variasi variabel dependen. $\mathrm{R}^{2}$ sama dengan 0 , maka tidak ada sedikitpun persentase sumbangan pengaruh yang diberikan variabel independen terhadap variabel dependen atau variasi variabel independen yang digunakan dalam model tidak menjelaskan sedikitpun variasi variabel 
dependen. Sebaliknya $\mathrm{R}^{2}$ sama dengan 1 , maka persentase sumbangan pengaruh yang diberikan variabel independen terhadap variabel dependen adalah sempurna, atau variasi variabel independen yang digunakan dalam model menjelaskan $100 \%$ variasi variabel dependen.

Menurut Sujarweni (2015:164) koefisien determinasi digunakan untuk mengetahui persentase perubahan variabel terikat yang disebabkan oleh variabel bebas.

\section{Uji t}

Digunakan untuk mengetahui pengaruh dan masing-masing variabel, baik variabel bebas terhadap variabel terikat yang signifikan secara statistik. Langkah-langkah pengujian uji t sebagai berikut : (Duwi Priyatno, 2008:57-58)

1. Menentukan Hipotesis

$\mathrm{H}_{0}$ : Tidak ada hubungan secara signifikan antara variabel independent dengan variabel dependent.

$\mathrm{H}_{\mathrm{a}}$ :Ada hubungan secara signifikan antara variabel independent dengan variabel dependent.

2. Menetukan tingkat signifikan

Pengujian menggunakan uji dua sisi dengan tingkat signifikan a $=5 \%$ (uji dilakukan 2 sisi karena untuk mengetahui ada atau tidaknya hubungan yang signifikan, jika 1 sisi digunakan untuk mengetahui hubungan lebih kecil atau lebih besar).

3. Menentukan t hitung

4. Menentukan t tabel

Tabel distribusi t dicari pada a $=5 \%: 2=2,5 \%$ (uji 2 sisi) dengan derajat kebebasan (df) $n-2$ $(\mathrm{df}=31-2=29$ yaitu sebesar 2,045)

5. Kriteria Pengujian

$\mathrm{H}_{\mathrm{o}}$ diterima jika $-\mathrm{T}$ Tabel $<\mathrm{T}$ hitung $<\mathrm{T}$ tabel

$\mathrm{H}_{\mathrm{o}}$ ditolak jika $-\mathrm{T}$ Hitung $<\mathrm{T}$ Tabel atau T Hitung $>\mathrm{T}$ Tabel

Berdasarkan probabilitas :

$\mathrm{H}_{0}$ diterima jika $\mathrm{P}$ value $>0,05$

$\mathrm{H}_{\mathrm{o}}$ ditolak jika $\mathrm{P}$ value $<0,05$

Membandingkan $t$ hitung dengan $\mathrm{t}$ tabel dan probabilitas

\section{HASIL DAN PEMBAHASAN}

\section{Uji Validitas}

Uji validitas adalah ketepatan atau kecermatan suatu instrumen dalam mengukur apa yang ingin diukur. Dalam penelitian ini jumlah responden sebanyak 31 orang. Dengan menggunakan tingkat signifikan 0,05, maka didapat $r_{\text {tabel }}$ sebesar 0,355. Jika $r_{\text {hitung }} \geq r_{\text {tabel }}$, maka instrumen atau item-item pertanyaan berkolerasi signifikan terhadap skor total (dinyatakan valid). Jika sebaliknya $r_{\text {hitung }}<r_{\text {tabel, }}$ maka item pernyataan dinyatakan tidak valid.

Berdasarkan data yang terkumpul dari tabel responden yang ditunjukkan dalam tabel berikut, maka terdapat 14 pernyataan untuk variabel $\mathrm{X}$ dan 12 pernyataan untuk variabel Y. Hasil analisis item ditunjukkan pada tabel berikut: 
Tabel 4. Hasil Analisis Item Pernyataan Variabel Y (Semangat Kerja) Item-Total Statistics

\begin{tabular}{|c|c|c|c|c|}
\hline & $\begin{array}{l}\text { Scale } \\
\text { Mean } \\
\text { if Item } \\
\text { Delete } \\
\text { d }\end{array}$ & $\begin{array}{c}\text { Scale } \\
\text { Varianc } \\
\text { e if Item } \\
\text { Deleted }\end{array}$ & $\begin{array}{l}\text { Correct } \\
\text { ed } \\
\text { Item- } \\
\text { Total } \\
\text { Correla } \\
\text { tion }\end{array}$ & $\begin{array}{l}\text { Cronbach's } \\
\text { Alpha if } \\
\text { Item } \\
\text { Deleted }\end{array}$ \\
\hline Pernyataan Y1 & 45,19 & 39,695 & ,578 & ,897 \\
\hline Pernyataan Y2 & 44,55 & 43,056 & ,511 & ,904 \\
\hline Pernyataan Y3 & 45,77 & 35,981 & ,705 & ,890 \\
\hline Pernyataan Y4 & 45,39 & 37,712 & ,534 & ,900 \\
\hline Pernyataan Y5 & 45,16 & 38,673 & ,645 & ,894 \\
\hline Pernyataan Y6 & 45,16 & 38,673 & ,645 & ,894 \\
\hline Pernyataan Y7 & 45,39 & 37,712 &, 534 & ,900 \\
\hline Pernyataan Y8 & 45,61 & 35,378 &, 746 & ,888 \\
\hline Pernyataan Y9 & 45,52 & 37,991 & ,629 & ,894 \\
\hline Pernyataan Y10 & 45,29 & 36,813 & ,816 & ,885 \\
\hline Pernyataan Y11 & 45,52 & 37,991 & ,629 & ,894 \\
\hline Pernyataan Y12 & 45,77 & 35,981 &, 705 & 890 \\
\hline
\end{tabular}

Sumber: Data Primer 2018 yang diolah

Dari tabel 4 diketahui, korelasi pernyataan pertama dengan skor total $=0,578$, maka dinyatakan valid. Hal ini di karenakan $r_{\text {hitung }}(0,578)$ lebih besar dari $r_{\text {tabel }}(0,355)$, untuk pernyataan butir 2 dan seterusnya dinyatakan valid karena $r_{\text {hitung }}$ lebih besar dari $r_{\text {tabel }}(0,355)$.

Tabel 5. Hasil Analisis Item Pernyataan Variabel X (Lingkungan Kerja) Item-Total Statistics

\begin{tabular}{lrcrr}
\hline & $\begin{array}{c}\text { Scale Mean } \\
\text { if Item } \\
\text { Deleted }\end{array}$ & $\begin{array}{c}\text { Sariance } \\
\text { if Item } \\
\text { Deleted }\end{array}$ & $\begin{array}{c}\text { Corrected } \\
\text { Item-Total } \\
\text { Correlation }\end{array}$ & $\begin{array}{c}\text { Cronbach's } \\
\text { Alpha if Item } \\
\text { Deleted }\end{array}$ \\
\hline Pernyataan X1 & 54,26 & 40,931 &, 707 &, 876 \\
\hline Pernyataan X2 & 53,87 & 42,983 &, 519 &, 886 \\
\hline Pernyataan X3 & 54,10 & 42,490 &, 779 &, 874 \\
\hline Pernyataan X4 & 54,35 & 42,570 &, 604 &, 881 \\
\hline Pernyataan X5 & 53,81 & 44,828 &, 501 &, 886 \\
\hline Pernyataan X6 & 54,10 & 39,957 &, 779 &, 872 \\
\hline Pernyataan X7 & 53,03 & 48,299 &, 558 &, 889 \\
\hline Pernyataan X8 & 53,87 & 42,983 &, 519 &, 886 \\
\hline Pernyataan X9 & 54,26 & 40,931 &, 707 &, 876 \\
\hline Pernyataan X10 & 53,61 & 45,845 &, 411 &, 889 \\
\hline Pernyataan X11 & 53,65 & 43,903 &, 635 &, 880 \\
\hline Pernyataan X12 & 53,71 & 44,080 &, 588 &, 882 \\
\hline Pernyataan X13 & 53,68 & 45,626 &, 491 &, 886 \\
\hline Pernyataan X14 & 53,29 & 46,880 &, 335 &, 892 \\
\hline Sumber: Data Prinan
\end{tabular}

Sumber: Data Primer 2018 yang diolah 
Dari tabel 5 diketahui, korelasi pernyataan pertama dengan skor total $=0,707$, maka dinyatakan valid. Hal ini di karenakan $r_{\text {hitung }}(0,707)$ lebih besar dari $r_{\text {tabel }}(0,355)$, untuk pernyataan butir 2 dan seterusnya dinyatakan valid karena $r_{\text {hitung }}$ lebih besar dari $r_{\text {tabel }}(0,355)$. Sedangkan butir pernyataan 14 dinyatakan tidak valid karena $r_{\text {hitung }}(0,335)$ lebih kecil dari $r_{\text {tabel }}(0,355)$ dan tidak diikutkan dalam uji reliabilitas.

\section{Uji Reliabilitas}

Uji reliabilitas digunakan untuk mengetahui konsistensi alat ukur, apakah alat pengukur yang digunakan dapat diandalkan dan tetap konsisten jika pengukuran tersebut diulang. Menurut Sekaran dalam Dwi Priyatno (2008:26), reliabilitas kurang dari 0,6 adalah kurang baik, sedangkan 0,7 dapat diterima dan di atas 0,8 adalah baik.

Berikut adalah hasil uji reliabilitas pada item pernyataan setiap Variabel.

Tabel 6. Tabel Uji Reliabilitas Pada Setiap Variabel

\begin{tabular}{lll}
\hline No & Variabel & $\begin{array}{l}\text { Cronbach's } \\
\text { Alpha }\end{array}$ \\
\hline 1 & Lingkungan Kerja (X) & 0,890 \\
\hline 2 & Semangat Kerja (Y) & 0,902 \\
\hline
\end{tabular}

Sumber: Data Primer 2018 yang diolah

Dari tabel 6 dapat dilihat bahwa cronbach's alpha pada setiap Variabel X dan Y diatas 0,6, hal ini berarti reliabilitas baik (reliable).

\section{Uji Regresi Linear Sederhana}

Regresi linear berganda digunakan untuk mengetahui arah hubungan antara variabel independen terhadap variabel dependen.

Tabel 7. Tabel Hasil Regresi Linear Sederhana

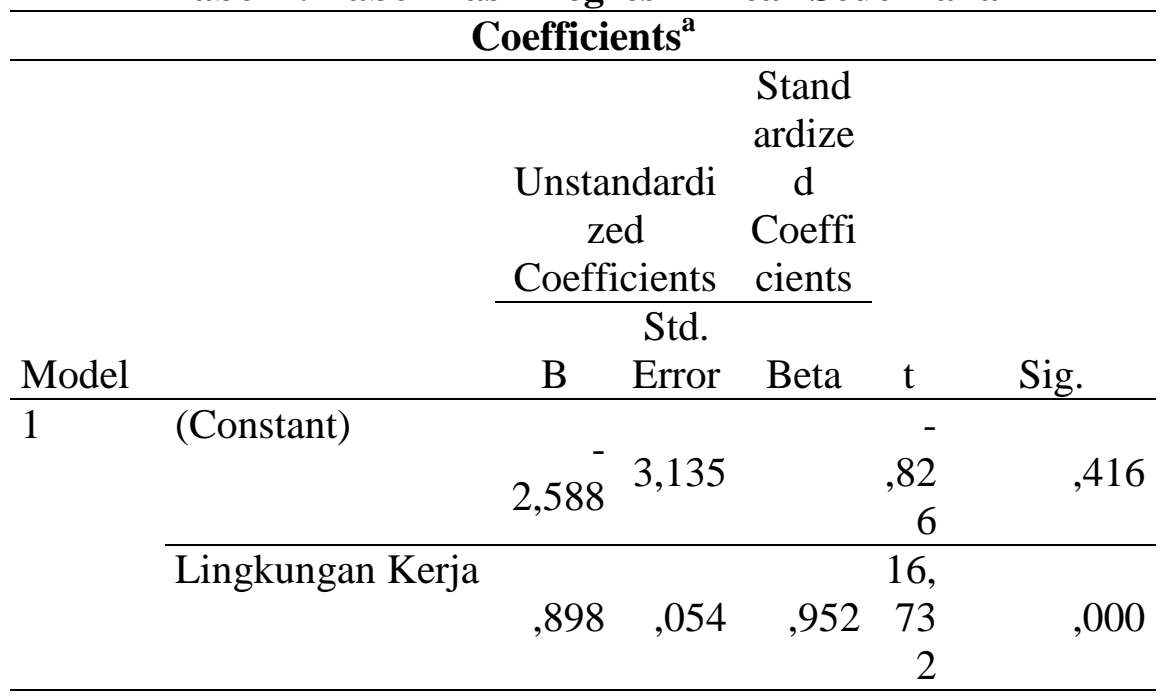

a. Dependent Variable: Semangat Kerja

Sumber: Data Primer 2018 yang Diolah

Dari tabel 7 diatas dapat dilihat hasil regresi linear berganda yaitu:

$\mathrm{Y}=-2,588+0,898 \mathrm{X}$. Dari hasil data tersebut dapat dijelaskan sebagai berikut:

a. Konstanta sebesar -2,588 artinya jika lingkungan kerja (X), bernilai 0, maka semangat kerja (Y) memiliki nilai dibawah (kurang dari) 2,588. 
b. Koefisien regresi Variabel lingkungan kerja (X) sebesar 0,898, artinya jika lingkungan kerja (X) mengalami kenaikan 1 satuan, maka semangat kerja guru SMK Negeri 1 UKUI akan mengalami kenaikan sebesar 0,898 satuan.

\section{Uji Koefisien Determinasi}

Tabel 8. Hasil Uji Koefisien Determinasi

\begin{tabular}{|c|c|c|c|c|}
\hline \multicolumn{5}{|c|}{ Model Summary $^{b}$} \\
\hline Model & $\mathrm{R}$ & $\begin{array}{c}\mathrm{R} \\
\text { Squa } \\
\text { re }\end{array}$ & $\begin{array}{c}\text { Adjusted } \\
\text { R } \\
\text { Square }\end{array}$ & $\begin{array}{l}\text { Std. Error of } \\
\text { the Estimate }\end{array}$ \\
\hline 1 & $\begin{array}{r}, 95 \\
2^{\mathrm{a}}\end{array}$ & ,906 & ,903 & 2,086 \\
\hline
\end{tabular}

a. Predictors: (Constant), Lingkungan Kerja

b. Dependent Variable: Semangat Kerja

Sumber: Data primer 2018 yang diolah

Dari tabel 8 dapat dilihat bahwa nilai $\mathrm{R}$ 0,952. Hal ini berarti variabel lingkungan kerja (X) memiliki hubungan yang sangat erat terhadap semangat kerja guru SMK Negeri 1 UKUI. Sedangkan nilai $\mathrm{R}$ square sebesar 0,906, hal ini berarti variabel lingkungan kerja (X) memberikan sumbangan pengaruh terhadap semangat kerja guru SMK Negeri 1 UKUI sebesar 90,6\% dan sisanya 9,4\% dipengaruhi oleh variabel lain yang tidak diteliti dalam penelitian ini.

Uji t

Tabel 9. Hasil Uji t

Coefficients $^{\mathbf{a}}$

\begin{tabular}{|c|c|c|c|c|c|c|}
\hline \multirow[b]{2}{*}{ Model } & & $\begin{array}{l}\text { Unstandardize } \\
\text { d Coefficients }\end{array}$ & $\begin{array}{l}\text { ardize } \\
\text { cients }\end{array}$ & $\begin{array}{c}\text { Standar } \\
\text { dized } \\
\text { Coeffic } \\
\text { ients } \\
\end{array}$ & \multirow[b]{2}{*}{$\mathrm{t}$} & \multirow[b]{2}{*}{ Sig. } \\
\hline & & B & $\begin{array}{l}\text { Std. } \\
\text { Error }\end{array}$ & Beta & & \\
\hline 1 & (Constant) & & & & - & \\
\hline & & $-2,588$ & 3,135 & & $\begin{array}{r}, 82 \\
6\end{array}$ & ,416 \\
\hline & $\begin{array}{l}\text { Lingkungan } \\
\text { Kerja }\end{array}$ & ,898 & ,054 & ,952 & $\begin{array}{r}16, \\
732\end{array}$ &, 000 \\
\hline
\end{tabular}

a. Dependent Variable: Semangat Kerja

Sumber: Data Primer 2018 yang Diolah

Dari tabel 9 Dapat dilihat bahwa nilai $\mathrm{t}_{\text {hitung }}$ didapat 16,732 lebih besar dari $\mathrm{t}_{\text {tabel }} 2,045$ dengan tingkat signifikasi 0,000 . Hal ini berarti lingkungan kerja berpengaruh signifikan terhadap semangat kerja guru SMK Negeri 1 UKUI.

Dari hasil penelitian diatas dapat dilihat bahwa lingkungan kerja berpengaruh positif dan signifikan terhadap semangat kerja guru SMK Negeri 1 UKUI. Hal ini berarti semakin lengkap dan baik lingkungan kerja akan meningkatkan semangat kerja guru SMK Negeri 1 UKUI. 


\section{KESIMPULAN}

Dari hasil penelitian yang telh dilakukan oleh penulis pada uraian sebelumnya mengenai Pengaruh Lingkungan Kerja Terhadap Semangat Kerja Guru Pada SMK Negeri 1 UKUI, maka dapat disimpulkan sebagai berikut:

a. Dilihat dari perhitungan uji-t, $t_{\text {hitung }}(16,732)$ lebih besar dari $t_{\text {tabel }}(2,039)$. Maka disimpulkan bahwa $\mathrm{H}_{\mathrm{a}}$ diterima dan $\mathrm{H}_{0}$ ditolak, jadi hipotesa yang menyatakan ada hubungan yang signifikan antara lingkungan kerja dengan semangat kerja guru pada SMK Negeri 1 UKUI dapat diterima.

b. Dilihat dari hasil Koefisien Determinasi, bahwa $\mathrm{R}^{2}$ sebesar 90,6\%, sedangkan 9,4\% dipengaruhi oleh faktor lain yang tidak diteliti dalam penelitian ini. Hal ini berarti lingkungan kerja memiliki pengaruh terhadap semangat kerja guru SMK Negeri 1 UKUI

\section{SARAN}

1. Hendaknya kenyamanan guru SMK Negeri 1 UKUI dapat diberikan secara maksimal, agar proses belajar mengajar berlangsung baik.

2. Hendaknya penerangan dalam ruangan dapat dimaksimalkan agar dapat menambah kenyamanan guru SMK Negeri 1 UKUI dalam melakukan proses pembelajaran.

\section{DAFTAR PUSTAKA}

[1].Alex S. Nitisemito, 2010. Manajemen personalia Manajemen Sumber Daya Manusia. Edisi Ketiga. Jakarta : Ghalia Indonesia.

[2].As’ad. 2003. Kepemimpinan Efektif Dalam Perusahaa. Ed. 2. Liberty. Yogyakarta.

[3].__ 2009. Seri Ilmu Sumber Daya Manusia: Psikologi Industri, Edisi IV. Yogyakarta: Liberty

[4].Ayu Maristiana. 2007. Analisis Pengaruh Motivasi Dan Penempatan Pegawai Terhadap Semangat Kerja Pada Dinas Tata Kota Bandar Lampung Jurnal Sains dan Inovasi III(2)123-130

[5].Analisa, Lucky Wulan. 2011. Analisis Pengaruh Motivasi Kerja Dan Lingkungan Kerja Terhadap Kinerja Karyawan (Studi Pada Disperindag Kota Semarang). Fakultas Ekonomi Universitas Diponegoro. Semarang

[6].Arikunto, Suharsimi, 2010. Prosedur Penelitian, Edisi Revisi, Rineka Cipta, Jakarta.

[7].Danim, S. (2012). Motivasi Kepemimpinan \& Efektifitas Kelompok. Jakarta: PT. Rineka Cipta.

[8].Fahmi, Irham. 2014. Perilaku Organisasi. Alfabeta. Bandung.

[9].Halsey, G. (2003). Supervising People (terjemahan). Jakarta : Rineka Cipta

[10].Hasibuan, S.P Melayu, 2012. Manajemen Sumber Daya Manusia, Edisi Revisi, Cetakan XVI, PT. Bumi Aksara, Jakarta. 
[11]. . 2016. Maanajemen Sumber Daya Manusia. Cetakan kesembilan. Bumi Aksara. Jakarta.

[12].Manullang, M, 2009. Dasar-Dasar Manajemen, Cetakan ke XXI, Gadjah Mada University Press, Yogyakarta.

[13].Mathis, Robert L. dan John H. Jackson. (2012). Manajemen Sumber Daya Manusia, Edisi Pertama. Salemba Empat, Jakarta

[14].Mardiana, Tri dan Muafi. 2001. Studi Empiris Stressor Terhadap Kinerja. Jurnal Siasat Bisnis (JSB). Vol.II. No.6.

[15].Masngudi dan M. Noor Salim. 2012. Metodologi Penelitian untuk Ekonomi dan Bisnis. Trianandra University Press. Jakarta.

[16].Mulyadi, Deddy. 2015. Perilaku Organisasi dan Kepemimpinan Pelayanan. Alfabeta. Baandung

[17].Nurlaily, Nurlaily. (2018). Upaya Meningkatkan Rasa Percaya Diri Siswa Dalam Mengemukakan Pendapat Melalui Layanan Bimbingan Kelompok. Jurnal Niara, 11(1), 71-76. Https://Doi.Org/10.31849/Nia.V11i1.1529

[18].Priyatno, Duwi, 2008. Mandiri Belajar SPSS (Statistical Product and Service Solution), MediaKom, Yogyakarta.

[19].Robbins, Stephen P. Dan Timothy A. Judge. 2008. Perilaku Organisasi Edisike-12. Jakarta. Salemba Empat.

[20].Sedarmayanti. 2011. Manajemen Sumber Daya Manusia. Reformasi Birokrasi dan Manajemen Pegawai Negeri Sipil (cetakan kelima). Bandung. PT. Refika Aditama.

[21].Saputra, Trio, Utami, Bunga, \& Sufi, Wasiah. (2018). Pengaruh Persepsi Mahasiswa Terhadap Kualitas Pelayanan Pegawai Dibagian Administrasi Fakultas Ilmu Administrasi Universitas Lancang Kuning. Jurnal Niara, 11(1), 6-16. Https://Doi.Org/10.31849/Nia.V11i1.1520

[22].Sondang P. Siagian. (2009). Kiat Meningkatkan Produktivitas Kerja. Jakarta: PT. Rineka Cipta

[23].Sinambela, Lijan Poltak. 2016. Manajemen Sumber Daya Manusia.Bumi Aksara. Jakarta

[24].Sugiyono, 2011. Metode Penelitian Administrasi, Cetakan XIX, Alfabeta, Bandung.

[25]. , 2010. Metode Penelitian Administrasi, Cetakan XVIII, Alfabeta, Bandung.

[26].Sujarweni, Viratna. 2015. Metodologi Penelitian Bisnis \& Ekonomi. Paper Plane. Yogyakarta

[27].Wilson, Bangun, 2012. Manajemen Sumber Daya Manusia, Erlangga, Jakarta. 